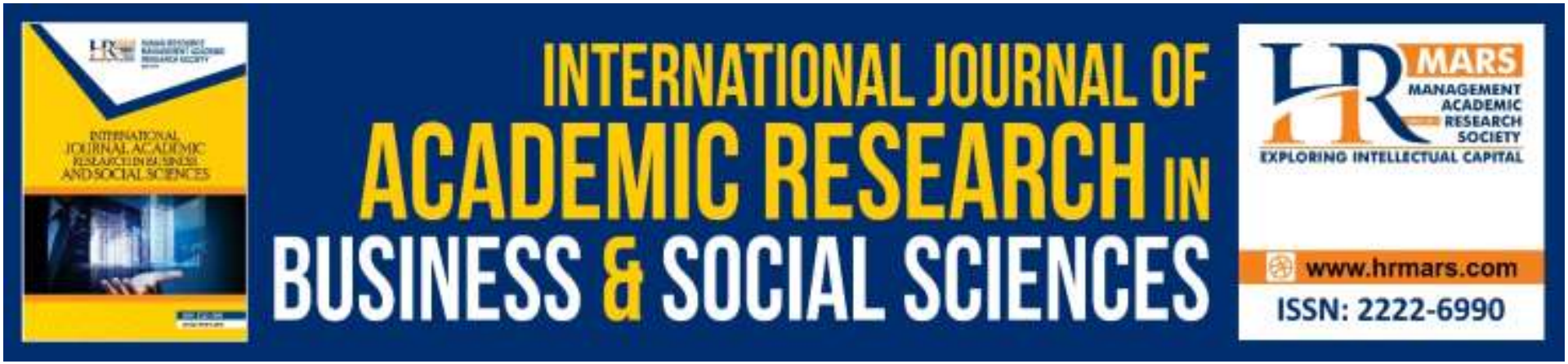

\title{
Transparency and Procurement Performance of Public Universities in Kenya: The Case of Moi University
}

\author{
Stella Cheminy Chesseto, Patrick Gudda, Munene Mbuchi
}

To Link this Article: http://dx.doi.org/10.6007/IJARBSS/v9-i9/6310

DOI: $10.6007 /$ IJARBSS/v9-i9/6310

Received: 05 June 2019, Revised: 10 July 2019, Accepted: 29 August 2019

Published Online: 09 September 2019

In-Text Citation: (Chesseto, Gudda, Mbuchi, 2019)

To Cite this Article: Chesseto, S. C., Gudda, P., Mbuchi, M. (2019). Transparency and Procurement Performance of Public Universities in Kenya: The Case of Moi University. International Journal of Academic Research in Business and Social Science. 9(9), 437-447.

\section{Copyright: (c) 2019 The Author(s)}

Published by Human Resource Management Academic Research Society (www.hrmars.com)

This article is published under the Creative Commons Attribution (CC BY 4.0) license. Anyone may reproduce, distribute, translate and create derivative works of this article (for both commercial and non-commercial purposes), subject to full attribution to the original publication and authors. The full terms of this license may be seen at: http://creativecommons.org/licences/by/4.0/legalcode

Vol. 9, No. 9, 2019, Pg. 437 - 447

Full Terms \& Conditions of access and use can be found at http://hrmars.com/index.php/pages/detail/publication-ethics 


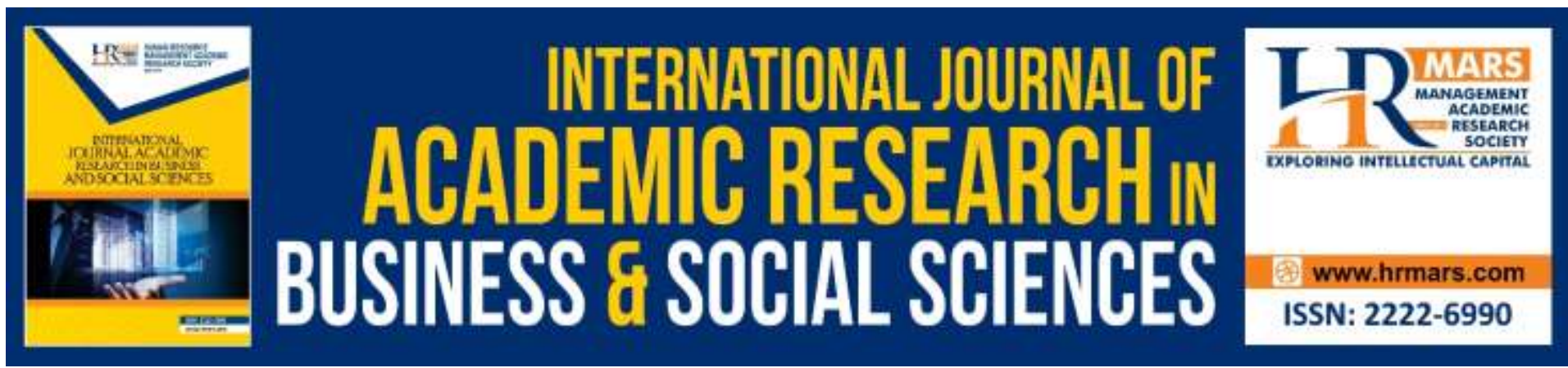

\title{
Transparency and Procurement Performance of Public Universities in Kenya: The Case of Moi University
}

\author{
Stella Cheminy Chesseto, Dr. Patrick Gudda, Mr. Munene \\ Mbuchi \\ Maasai Mara University \\ Email: cstella@mmarau.ac.ke,guddap@mmarau.ac.ke,munenembuchi@gmail.com
}

\begin{abstract}
In the modern competitive business climate, procurement entities painstakingly focus on getting technologically advanced goods and services that have no defect in a timely and costeffective manner. Often suppliers lack the ability to perform adequately in one or more of this area. It is against this background that this study sought to determine the effects of transparency on procurement performance. This was undertaken through the following specific objectives; to analyze the effects of frequency of communication on procurement performance; assess the effect of giving repeat orders on procurement performance; evaluate the effects of buyer-supplier meetings on procurement performance and the effects of giving additional information on procurement performance. This study adopted the social exchange theory. Moi University was selected using cluster sampling technique. Census technique was used to get the sample size. Data was obtained using structured questionnaires. A pilot test was carried out to establish the validity and reliability of the questionnaires. A reliability coefficient of above 0.7 was accepted for this study. Data was analyzed using both descriptive and inferential statistics. Findings indicated that the variables are statistically significance to influencing procurement performance. Public universities ought to communicate frequently with their suppliers, and in case any additional information is required, each party should be free to give out additional information. Public universities also need to give repeat orders to their suppliers whom they have vetted and have proved to be valuable asset. Buyer- supplier meetings should be held frequently this will ensure issues are discussed; challenges are addressed.
\end{abstract}

Keywords: Procurement Transparency and Procurement Performance.

\section{Introduction}

Procurement transparency is open, frequent and collaborative communication between buyer and supplier. Transparency benefits the buying firms, as it fosters a climate of mutual support, thereby improving customer responsiveness among channel partners, effective communication improves the buying firm's performance (D'amourset et al., 1999) and is an important factor in the development of supply management capability. Feedback is essential 
in any form of communication between parties. When buyers treat their suppliers as partners and share strategic information with them, they achieve better lead times, quality products, increase operating flexibility and establish long term cost reductions. Frequent and timely communication improves performance (Korir, 2015). Effective communication enhances levels of coordination, satisfaction, commitment and performance (Goodman and Dion 2001; Mohr and 1990). Effective communication is crucial in maintaining a long-term buyer supplier relationship and achieves high performance (Mohr and Nevin 1990; Morgan and Hunt 1994).Transparency is an idea that is linked to accountability in the sense that by frequently giving out information on how decisions are made, as well as measures of performance, public deliberation can be improved, accountability will be strengthen and there will be informed citizen choice.

The Procurement process should uphold integrity by ensuring that there are no malpractices; informed decision-making, which requires public bodies to base decisions on accurate information and ensure that requirements are being met. More still, the Procurement practice should be responsive to aspirations, expectations and needs of the target society. There is need for transparency to enhance openness and clarity on procurement policy and its delivery (World Bank, 2003). The system of public procurement depends crucially on the availability and transparency of information not only about the current calls for bids and procedures, but also the history of purchases and predictions of future demand for goods and services. The availability of current information attracts more suppliers, increases competition and creates the environment for efficient procurement (Ohashi, 2009). Transparency leads to trust and when both parties trust each other; there will be ways by which parties work out difficulties. Trust has the strongest effect on achieving cooperation in relationship and performance.

Riju et al (2009) argue that managing information and information flow in an effective manner means not only the availability of information exchanged but also a more accurate and detailed body of information which will influence the supply chain partners performance as well as leading to successful relationships, therefore with the growing technological advances and the emergence of the global information infrastructure, the company should possess the suitable competitive inter-organizational information system to enable them achieve rapid and effective response to the customer needs and changing expectations. By sharing information, the supply chain partners can develop more opportunities such as matching the available information to modify their courses of actions and future planning which can have a positive and a direct effect on the company and its supplier relationships (HSU et al., 2008). The indicators that were used to measure transparency in this study include; frequency in communication, number of repeat orders, frequency of accessibility of information and frequency of buyer-supplier forums.

Procurement performance is the degree to which procurement function is able to achieve its set goals using minimum resources. Measuring performance provides the basis for an organization to assess how well it is progressing towards its pre-determined objectives, identifies areas of strengths and weaknesses and decides on future initiatives with the goal of how to initiate performance improvements. It helps an organization realize its importance 
towards business profitability and maintaining a long-term competitive advantage. It is away to improve business and leads to successful organization, it keeps an organization on tract in achieving organizational objectives, increases profits, enlarging market and strengthen existence. According to Patrick (2010) it is important to measure procurement performance as it provides response on whether the planned outcomes have been achieved, it also provides information for decision making at both the departmental level and the entire organization level, it enables Management to recognize procurement functions and finally provide emphasis and motivation for staff at the purchasing unit.

Certain key performance indicators can help business understand its purchasing habits and indicate superior or inferior performance. Delivery on time is the first key step to supply chain excellence and leads to customer satisfaction (Steward, 1995). Timely delivery means superior performance and vice versa. Completeness of deliveries means superior performance, receiving incorrect order, either too much quantity or too little indicates financial problems, production issues, poorly trained personnel. Timely payments indicate superior performance and vice versa. (korir,2015). Unit cost refers to cost of procurement in terms of resources/time, cheap product indicates inferior quality, and organizations must ensure goods are procured/sold within the market range. Quality refers to adhering to specifications, this indicates superior performance and vice versa (Kohl et al, 2009 \& Gooh et al, 2009) Winser and Tan (2000) puts quality as a criterion of performance. Tan et al (1999) argues that quality has a positive impact on growth and return on assets. Performance indicators for this study were number of reduced orders, processing of invoices, and processing of emergency orders.

\section{Objectives of the Study}

General objective is to determine the effects of transparency on procurement performance of public Universities in Kenya.

\section{Specific Objectives}

i. To analyze the effects of frequency in buyer -supplier forums on procurement performance in public Universities in Kenya.

ii. To assess the effect of frequency of communication on procurement performance in public Universities in Kenya.

iii. To assess the effect of frequency of repeat orders on procurement performance in public Universities in Kenya.

iv. To assess the effect of frequency of giving additional information on procurement performance in public Universities in Kenya.

\section{Research Hypothesis}

H01: There is no significant effect of frequency in buyer -supplier forums on procurement performance in public Universities in Kenya.

H02: There is no significant effect of frequency of communication on procurement performance in public Universities in Kenya.

H03: There is no significant effect of frequency of repeat orders on procurement performance in public Universities in Kenya. 
H04: There is no significant effect of frequency of giving additional information on procurement performance in public Universities in Kenya.

\section{Literature Review \\ Theoretical Review \\ Relationship Marketing Theory}

According to Sheth \& Parratiyar (1995), the formation of relationship between parties takes into consideration the non-financial aspects like trust and level of commitment. This theory focuses on utilizing tools of traditional marketing in establishing long term value for customers. The theory suggests that the strength of its relationship with the customer will improve as the company gives value to customers, and hence will increase customer retention. This theory is relevant to transparency and procurement performance as it concentrates on the collaborative long-term relationships with pre-qualified suppliers through mutual co-operation and interdependence.

\section{Social Exchange Theory}

This theory was developed by Rusell Cropanzo\&Marle Mitchell (2001), the main proponents were Brass et al (2004), Konovky (2000), Coyle et al (2004) and Ruppet et al (2001). The theory has three fundamental ideas: the rules and norms of exchange, the resources exchange and the relationship that emerges i.e. relationship evolve over time into trust, loyalty and mutual commitments and that both parties in the relationship must abide by certain rules. In addition, exchange between parties is beyond the material properties and include love, information, money among others and finally workplace experience leads to interpersonal connections. Cropanzo et al (2001). The main weakness of the theory is that the social exchange theory constructs have not been fully identified and some formulations are ambiguous lending themselves to multiple interpretation. This theory is significant because of its emphasis on trust and commitments by parties involved in the procurement process.

\section{Conceptual Framework}

The conceptual framework shows the interdependence of transparency and procurement performance measured by the following indicators: buyer-supplier forums, frequency of communication, repeat orders and giving additional information.

\section{Buyer-Supplier Forums and Procurement Performance}

Transparency, throughout the public procurement process is instrumental in preventing conflict of interest, corruption, misuse of public resources, as well as ensuring fair competition; this can only be created through an effective procurement forum between the buyers and the suppliers. (OECD,2010). Buyer-Supplier forums enhance the procurement process and helps build trust and commitment (Riju et al.2009).

\section{Frequency of Communication and Procurement Performance}

Communication is the formal as well as the informal sharing of meaningful and timely information (Anderson and Narus, 1990). Procurement entities use different forms of media to communicate e.g. telephones, mail, E-mail, EDI etc. (Rodrigo, 2009) Frequent and collaborative communication with key suppliers benefits the buying firms in the long run, as it fosters a climate of mutual support, thereby improving customer responsiveness among 
channel partners. Effective communication enhances levels of coordination, satisfaction, commitment and performance (Goodman and Dion 2001; Mohr and 1990). Korir (2015) established that frequent and timely communication improves performance.

\section{Repeat Orders and Procurement Performance}

This is when vetted suppliers are constantly given orders repeatedly, this is a sign of Trust, reliability and commitment between buyer and suppliers, this greatly improves procurement performance as there would be continuity of timely supplies and organization will not see the need to stock supplies which in turn will reduce costs and improve performance.

\section{Additional Information and Procurement Performance}

Communication positively influences procurement performance as organizations let their supplier know what is expected and keep each other informed about issues that may affect partner, in addition communicating builds trust and through trust parties are concerned about each other and each will give the best. Organization need to communicate in order to coordinate the flow of products from suppliers to buyers, products prices and contractual agreements require discussions, delivery schedules and information about technical adaptations need to be exchanged and occasionally make developments on other strategic issues (Zhouand,2007).Effective information sharing enhances visibility and reduces uncertainty and can create opportunities for firms to work collaboratively which enhances procurement performance.

This conceptual is therefore summed up in figure .1

\section{TRANSPARENCY \\ - Buyer-supplier forums \\ - Frequent Communication \\ - Repeat orders \\ - Additional information}

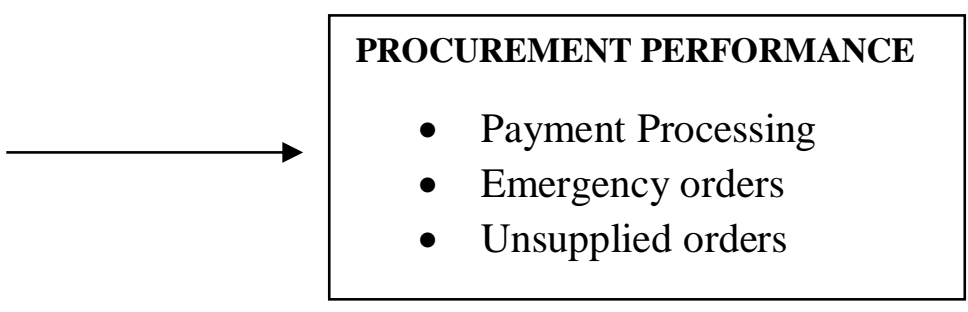

Dependent Variable

Figure 1: Conceptual Framework

\section{Empirical Review}

Inayat (2012) in his research concluded that the core issue in procurement performance is trust, when the buyer trusts his supplier; it positively affects supplier performance and ultimately the organization performance. Communication that is effective plays a major part in societal and corporate relationships and that restricted information flow impedes supply chain relationship and finally affects supply chain performance (Irene,2012). Honest communication between parties, involvement, knowing expectation and technology are the secrets to handle relationship between the buyer and the supplier (Mickey, 2015) Melody et al. (2013) highlighted the following variables that positively influences procurement performance i.e. communication, cooperation, interpersonal relationship and power dependence Walter et al (2013) listed collaboration, trust and closeness as variables 
affecting procurement performance, all the factors listed positively affect procurement performance. Bart \&Akkermans (2009) concluded that five relationship variables are key; commitment, conflict, economic and non-economic satisfaction and trust; however the researcher did not look at the effects of the five variables on organizational performance. Literature reviewed revealed that studies that have been carried focused on other elements such as trust, honest, monitoring, analysis, need definition among others affecting procurement performance, Therefore, the study on transparency incorporating the indicators mentioned in the study and its effects on procurement performance in public universities has not been done, in addition, most studies have been done on private rather than on government suppliers. Besides; literature review has not answered the specific objectives of the research as cited in the research problem statement, this study therefore, seeks to examine those aspects that emerged but left out in previous studies.

\section{Research Methodology Research Design}

A cross-sectional -survey research design was used. This research design was preferred because the researcher was to collect data at one point in time translating to ease of data gathering and assessment, short study duration and moderate cost. There were different groups identified for the study i.e. the buyers and the suppliers and this research design is best for such scenarios, finally it enables data to be collected from a large number of samples. This study adopted primary data collection method; this was achieved through the use of group administered questionnaires, self-administered questionnaires and mail -out questionnaires.

\section{Sample Size and Sampling Technique}

The study targeted all the thirty-one public universities in Kenya. The researcher used cluster sampling technique, this method was preferred since there is homogeneity among public universities in Kenya and therefore selection of any one university allows for generalization of the results as well as mutual exclusivity. The target respondents comprised of procurement and finance profession from each of the public university. The researcher had twenty-four clusters; from the clusters, the researcher used simple random sampling to select Moi University which has a total of 60 professional staff at Procurement and Finance department; in addition, the university has 140 pre-qualified suppliers. Census technique was used to get the sample size. All the pre-qualified suppliers and members of staff were used as sample size because the population was not vast and it enabled the researcher to have minimum bias and reduce errors in interpreting data collected.

\section{Data Analysis Procedure}

After data was collected by the researcher, it was coded, checked for completeness edited transformed and organized into a database via the statistical package for social sciences (SPSS) version 20 which facilitated accurate and efficient analysis of inferential statistics. Once the coding procedures had been established, reliable output was delivered. The information was displayed by use of tables. Regression analysis was used to determine the degree of relationship in the patterns of variation through the calculation of the coefficient of correlation which was used to test hypothesis of the study. Multiple linear regression analysis 
was used to analyze the overall effect of the independent variables and the dependent variable.

\section{Results}

\section{Transparency and Procurement Performance}

Respondents were asked questions relating to frequency of repeat orders, frequency of buyer-supplier forums, frequency in communication, frequency of additional information. The results are presented table 1 and 2 .

Table 1: Transparency and Procurement Performance (Descriptive statistics)

\begin{tabular}{|c|c|c|c|c|c|c|c|c|}
\hline & \multicolumn{2}{|c|}{ 0-10 times } & \multicolumn{2}{|c|}{ 11-15times } & \multicolumn{2}{|c|}{ 16-20times } & \multicolumn{2}{|c|}{ Above 20times } \\
\hline & Freq & $\%$ & Freq & $\%$ & Freq & $\%$ & Freq & $\%$ \\
\hline Communication & 5 & 2.7 & 5 & 2.7 & 48 & 26.1 & 126 & 68.5 \\
\hline additional info. & 5 & 2.7 & 4 & 2.2 & 35 & 19.0 & 140 & 76.1 \\
\hline repeat orders & 31 & 16.3 & 8 & 4.3 & 49 & 26.6 & 96 & 52.2 \\
\hline B-S Meeting & 4.0 & 2.2 & 6.0 & 3.3 & 60 & 32.6 & 114 & 62.0 \\
\hline
\end{tabular}

From table 1 ; The results shows that the majority of the respondent's (52.2\%) process more than 20 repeat orders, (68.5\%) communicate frequently more than 20 times with each other, (76.1\%) provide additional information and (62\%) have attended buyer-supplier forums more than 20 times. This implies that there is a high level of information sharing between the buyer and the supplier which translates to transparency between the buyer and the supplier and this enhances their relationship which in turn improves Procurement Performance. This concurs with the findings of Dave (2007) who argued that buyer-supplier meetings build relationship and improves performance as compliance, conduct and strategic financing issues are addressed. The findings are also in line with findings of Korir (2015) who established that frequent and timely communication improves performance. Effective communication enhances levels of coordination, satisfaction, commitment and performance (Goodman and Dion 2001; Mohr and 1990). Effective communication is crucial in maintaining a long-term buyer supplier relationship and achieves high performance (Mohr and Nevin 1990; Morgan and Hunt 1994). 
From table 2, the results of the regression indicated the predictor explained $48 \%$ of the variance $\left(R^{2}=.48 .3 ; R^{2}\right.$ adj $\left.=.471\right), P<.05$ i.e. $48 \%$ of variations in procurement performance are explained by variations in transparency. indicating that transparency has an impact on procurement performance. This agrees with the findings of D"amours et al., (1999), who found that transparency improves buying firm's performance and the findings of Bethline et al (2019) and Karanja et al (2015) who noted that transparency affects procurement performance. From table 2, the results imply that if parties involved in the procurement process freely communicate with each other, hold meetings, give additional information and give repeat orders then it is expected that procurement performance would improve in terms of completeness of delivery and faster processing of invoice and emergency orders. Further,

Table 2: Transparency and Procurement Performance (Inferential Statistics)

\begin{tabular}{llllll} 
Model & \multicolumn{2}{l}{ Unstandardized Coefficients } & $\begin{array}{l}\text { Standardize } \\
\text { Coefficients }\end{array}$ & T & Sig. \\
& B & $\begin{array}{l}\text { Std. Error } \\
\text { Beta }\end{array}$ & & \\
(Constant) & 2.641 & .470 & & 5.624 & .000 \\
\hline communication & .068 & .110 & 049 & .620 & .036 \\
additional info & .083 & .097 & .068 & .859 & .012 \\
repeat orders & .562 & .046 & .744 & 12.192 & .000 \\
B-S Meeting & .162 & .076 & 130 & 2.135 & .034 \\
\hline
\end{tabular}

$\mathrm{R}=.695^{\mathrm{a} ;} \mathrm{R}^{2}=.483 \mathrm{R}^{2} \mathrm{adj}=.471 ; p \leq 0.05$

the null hypotheses that there is no significant effect of frequency in buyer-supplier forums on procurement performance; there is no significant effect of frequency of communication on procurement performance ; there is no significant effect of frequency of repeat orders on procurement performance and finally there is no significant effect of frequency of giving additional information on procurement are rejected and the alternative hypotheses are accepted; this is supported with a $p<.05$.

\section{Conclusion and Policy Implications}

The findings showed that the independent variables considered in the regressions i.e. provision of additional information, frequent communication, buyer-supplier meetings and repeat orders as measures of transparency were statistically significance to influencing procurement performance of public universities as indicated by the $p$-values being less than 0.05.This means that transparency is depended upon to make conclusions about procurement performance of public universities in Kenya.

Public universities must be transparent while conducting their procurement activities. They can achieve this by communicating frequently with their suppliers, giving repeat orders to their suppliers whom they have vetted and have proved to be valuable asset, having Buyersupplier meetings frequently as this will ensure issues are discussed and challenges addressed before they go out of hand, finally both the buyer and the supplier should be free to give out additional information as effective information sharing enhances visibility and reduces uncertainties. 


\section{References}

Boddy, D., Macbeth, D. and Wagner, B. (2000). Implementing collaboration between organizations: an empirical study of supply chain partnering. Journal of Management studies, 37(7), pp.1003-1018.

Eisenhardt, K. M. (1989). Agency theory: An assessment and review. Academy of management review, 14(1), pp.57-74.

Goodman, L. E. and Dion, P. A. (2001). The determinants of commitment in the distributormanufacturer relationship. Industrial Marketing Management, 30(3), pp.287-300.

Kiage, J. O. (2013). Factors affecting procurement performance: A case of ministry of energy. International journal of business and commerce, 3(1), pp.54-70.

Korir, S., Rotich, J. and Bengat, J. (2015). Performance management and public service delivery in Kenya. European Journal of Research and Reflection in Management Science, 3(4).

Kothari, C. R. (2003). Research Methodology: Methods and Techniques New Delhi: Wishwa Prakashan.

Monczka, R. M., Handfield, R. B., Giunipero, L. C. and Patterson, J. L. (2015). Purchasing and supply chain management. Cengage Learning.

Mohr, J. and Spekman, R., (1994). Characteristics of partnership success: partnership attributes, communication behavior, and conflict resolution techniques. Strategic management journal, 15(2), pp.135-152.

Nooteboom, B. (2002). A Balanced Theory of Sourcing, Collaboration and Networks, Rotterdam School of Management. Report ERS-2002-24-ORG.

Weele, V. A. J. (2002). Purchasing and supply chain management: Analysis, planning and practice, 3. Aufl., Padstow, Cornwall.

Peters, L. D. and Fletcher, K. P. (2004). Communication strategies and marketing performance: An application of the Mohr and Nevin framework to intra-organisational crossfunctional teams. Journal of Marketing Management, 20(7-8), pp.741-770.

Yadav, S., Yadav, A. and Kushwaha, N., (2013). The Bullwhip Effect-Impact of Lead Time, Information Quality, and Information Sharing. International Journal of Engineering and Technical Research, 1.

Yang, Y. C. and Hsu, J. M., (2010). Organizational process alignment, culture and innovation. African Journal of Business Management, 4(11), pp.2231-2240. 